\title{
Cobalt Spinel Nanocubes on N-Doped Graphene: A Synergistic Hybrid Electrocatalyst for the Highly Selective Reduction of Carbon Dioxide to Formic Acid
}

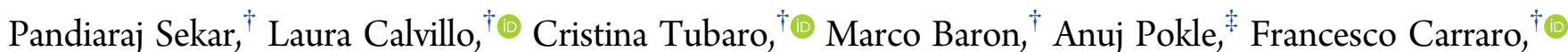
Alex Martucci, ${ }^{\S}$ and Stefano Agnoli* ${ }^{\dagger \dagger}$

${ }^{\dagger}$ Department of Chemical Science, University of Padova, Via F. Marzolo 135131 Padova, Italy

${ }^{\ddagger}$ School of Physics and CRANN, Trinity College Dublin, Dublin 2, Ireland

${ }^{\S}$ Department of Industrial Engineering, University of Padova, via F. Marzolo 9, 35131 Padova, Italy

\section{Supporting Information}

ABSTRACT: Carbon dioxide reduction into useful chemical products is a key technology to address urgent climate and energy challenges. In this study, a nanohybrid made by $\mathrm{Co}_{3} \mathrm{O}_{4}$ and graphene is proposed as an efficient electrocatalyst for the selective reduction of $\mathrm{CO}_{2}$ to formate at low overpotential. A comparison between samples with different metal oxide to carbon ratios and with or without doping of the graphene moiety indicates that the most active catalyst is formed by highly dispersed and crystalline nanocubes exposing $\{001\}$ oriented surfaces, whereas the nitrogen doping is critical to obtain a controlled morphology and to facilitate a topotactic transformation during electrocatalytic conditions to $\mathrm{CoO}$, which results in the true active phase. The nanohybrid made up by intermediate loading of $\mathrm{Co}_{3} \mathrm{O}_{4}$ supported on nitrogen-doped graphene is the most active catalyst, being able to produce 3.14 mmol of formate in $8 \mathrm{~h}$ at $-0.95 \mathrm{~V}$ vs SCE with a Faradaic efficiency of $83 \%$.

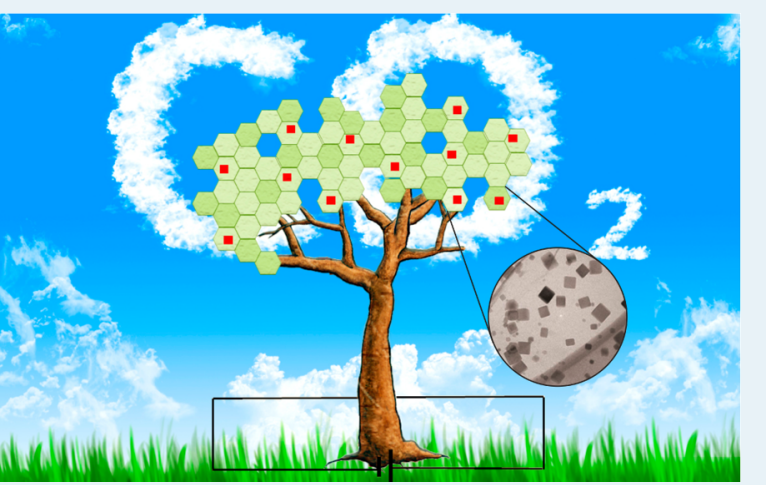

KEYWORDS: $\mathrm{CO}_{2}$ reduction, graphene, nanocomposites, metal oxide, electrocatalysts

\section{INTRODUCTION}

Due to its high energy efficiency and environmental sustainability, the electrochemical $\mathrm{CO}_{2}$ reduction reaction (CO2RR) is a promising method for converting readily available $\mathrm{CO}_{2}$ into added-value feedstocks such as $\mathrm{CO}, \mathrm{CH}_{4}$, $\mathrm{HCOOH}$, and other small organic molecules. ${ }^{1-5}$ This process has the 2-fold benefit of consuming $\mathrm{CO}_{2}$, whose emission in the environment is posing serious concerns, and producing different types of fuels, possibly using renewable energy sources such as solar radiation. ${ }^{6-8}$ Unfortunately, at the present state of technology, the sluggish kinetics and formation of multiple products in CO2RR hinder its large-scale application. ${ }^{9,10}$ Hence, great research efforts are currently being made to develop improved electrocatalysts with high product selectivity at low overpotential. ${ }^{11}$ Among metals, Cu-, Au-, Pd-, and Agbased electrocatalysts have shown the highest conversion rates for the CO2RR. ${ }^{12-19}$ Unfortunately, these materials generally suffer from poor product selectivity, activity loss due to catalyst poisoning, and relatively high cost and limited availability. Therefore, the development of new electrocatalysts with high selectivity and durability made up of cheap and abundant materials still remains a highly challenging task.
Recently, nanostructured metal oxide based electrocatalysts have displayed quite interesting performances for the CO2RR, in terms of selectivity, durability, and fast kinetics. Among the various metal oxides, $\mathrm{Co}_{3} \mathrm{O}_{4}$-based catalysts have been thoroughly studied as electrocatalysts for water oxidation, oxygen reduction reaction, hydrogen evolution reaction, etc. $^{20-25}$ The origin of the electrochemical activity in nanostructured spinel $\mathrm{Co}_{3} \mathrm{O}_{4}$ mainly stems from the presence of mixed oxidation states $\left(\mathrm{Co}^{2+}\right.$ in tetrahedral and $\mathrm{Co}^{3+}$ in octahedral sites) and by the presence of highly active surface sites. ${ }^{26}$ Gao et al. reported that ultrathin layers of $\mathrm{Co}_{3} \mathrm{O}_{4}$ show high $\mathrm{CO}_{2}$ reduction activity and are very selective for the formation of formic acid. ${ }^{27}$ The special activity was connected not only to the increased number of surface sites typical of lowdimensional systems, but also to the peculiar electronic structure of the ultrathin films that endows the material with easy electronic transfer, fast carrier transport, and low corrosion rate. Recently, the same group has reported that thin layers of partially oxidized cobalt exhibit an excellent catalytic activity

Received: July 3, 2017

Revised: September 23, 2017

Published: September 28, 2017 
toward the CO2RR. The origin of such activity is not completely understood, but it seems to be a combination of nanoconfinement of metal atoms that are able to promote a first electronic transfer to $\mathrm{CO}_{2}$ and the presence of an oxide phase that favors the adsorption of $\mathrm{CO}_{2}$ and additionally catalyzes the $\mathrm{H}^{+}$transfer. ${ }^{28}$ The analysis of these works therefore indicates that $\mathrm{Co}_{3} \mathrm{O}_{4}$ is a very promising catalyst, but its properties such as poor electron conductivity, limited surface area, and inefficient electron transfer have to be ameliorated by a careful nanodesign. The same goal, however, can be achieved in a simple and effective way by creating a composite material. Following this approach, the electrical conductivity and surface area problems could be overcome by coupling $\mathrm{Co}_{3} \mathrm{O}_{4}$ with different carbon-based materials such as graphene, carbon nanotubes, fibers, etc. ${ }^{29}$ Owing to its high surface area, electrical conductivity, mechanical stability, and easily controllable surface chemistry, graphene is the best candidate to support metal oxide nanoparticles (NPs). ${ }^{30}$ In addition, the introduction of heteroatoms $(\mathrm{N}, \mathrm{B}$, and $\mathrm{S})$ into the graphene backbone could create additional catalytically active sites and provide a large amount of nucleation centers for the NPs. ${ }^{31-35}$ Moreover, graphene can facilitate electron transport and improve the NP electronic connection to the electrode. Actually, some of the best-performing catalysts for different electrochemical reactions such as the OER and ORR are based on graphene $/ \mathrm{Co}_{3} \mathrm{O}_{4}$ nanocomposites. ${ }^{29}$ Quite interestingly, in a recent work, Wu et al. $^{36}$ have reported that $\mathrm{N}$-doped graphene $(\mathrm{NG})$ shows some activity for the conversion of $\mathrm{CO}_{2}$ into $\mathrm{CO}$ due to the change in the density of states created by doping. ${ }^{37}$ Moreover, the combination of $\mathrm{N}$-doped graphene with cobalt-based compounds is particularly interesting for catalytic application, since it mimics the active centers that are found in several natural catalysts $^{38}$ and, similarly, Co-porphyrin-based metal-organic frameworks have demonstrated to be quite efficient for the CO2RR ${ }^{39-44}$ By considering all the aforementioned facts, herein we have developed a simple and highly scalable procedure for the synthesis of a special nanocomposite that comprises cubic spinel $\mathrm{Co}_{3} \mathrm{O}_{4} \mathrm{NPs}$ and $\mathrm{NGr}\left(\mathrm{NG}-\mathrm{Co}_{3} \mathrm{O}_{4}\right)$. This nanocomposite was optimized with the aim of combining the high catalytic activity of $\mathrm{Co}_{3} \mathrm{O}_{4}$ together with the excellent electronic properties of NGr. Eventually, this approach has produced a hybrid material that has shown a very high activity toward the reduction of $\mathrm{CO}_{2}$ to formic acid with high selectivity at very low overpotential.

\section{RESULTS}

Scheme 1 illustrates the synthesis protocols for the preparation of $\mathrm{NG}-\mathrm{Co}_{3} \mathrm{O}_{4}$ and reduced graphene (RG)- $\mathrm{Co}_{3} \mathrm{O}_{4}$ nanocomposites. This route takes advantage of a low-temperature hydrothermal step for the preparation of intimately connected cobalt oxide/graphene composites, which are characterized by highly crystalline oxide NPs supported on highly dispersed single- or few-layer graphene sheets.

The morphology, size, and crystallinity of the $\mathrm{Co}_{3} \mathrm{O}_{4} \mathrm{NPs}$ on $\mathrm{NG}$ were studied by TEM. Figure 1 shows representative TEM images of the NG- $\mathrm{Co}_{3} \mathrm{O}_{4}-30$, NG-Co $\mathrm{O}_{4}-40$, and $\mathrm{RG}-\mathrm{Co}_{3} \mathrm{O}_{4}-30$ samples, whereas the particle size distribution is reported in Figure $\mathrm{S} 1$ in the Supporting Information. Figure la,d shows that the $\mathrm{Co}_{3} \mathrm{O}_{4} \mathrm{NPs}$ of NG-Co $\mathrm{O}_{4}-30$ have a cubic shape with an average size of 25-30 nm (Figure $\mathrm{S} 1$ ) and are uniformly distributed on the NG sheets. The $\mathrm{Co}_{3} \mathrm{O}_{4}$ nanocubes are highly crystalline, as confirmed by the selected area electron diffraction (SAED) pattern (Figure S2b in the Supporting Information).
Scheme 1. Various Methods Involved in the Synthesis of $\mathrm{NG}-\mathrm{Co}_{3} \mathrm{O}_{4}$ and $\mathrm{RG}-\mathrm{Co}_{3} \mathrm{O}_{4}$ Electrocatalysts

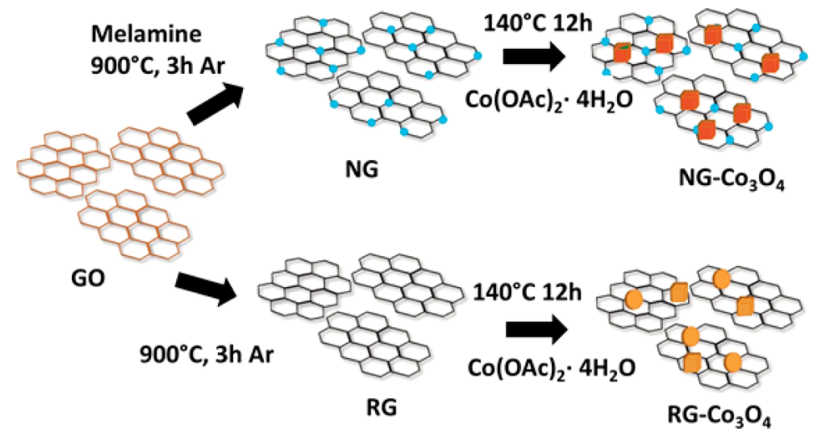

The NPs preferentially expose the $\{100\}$ surface plane, as may be deduced from the lattice fringes with a periodicity of 0.289 $\mathrm{nm}$ observed in Figure 1g, corresponding to $\{220\}$ crystal planes, which are cutting at $45^{\circ}$ the surface planes of the nanocubes. The origin of the cubic morphology can be ascribed to the use of cobalt acetate as a precursor without the addition of any base. This leads to a synthesis environment with a low concentration of hydroxyl ions, which favors the faster growth of $\{111\}$ over $\{100\}$ facets, resulting in the formation of cubes. ${ }^{45,46}$

The TEM analysis also provides information about the effect of the $\mathrm{Co}_{3} \mathrm{O}_{4}$ loading on the morphology of the $\mathrm{Co}_{3} \mathrm{O}_{4} \mathrm{NPs}$. Figure $1 \mathrm{~b}$,e shows an increase in the average particle size (35$40 \mathrm{~nm}$ ) for the NG- $\mathrm{Co}_{3} \mathrm{O}_{4}-40$ sample, in comparison with NG$\mathrm{Co}_{3} \mathrm{O}_{4}-30$, although the cubic shape is maintained. In this sample, some agglomerates are also observed due to the higher loading of $\mathrm{Co}_{3} \mathrm{O}_{4}$. In high-magnification images, it is possible to distinguish clearly the presence of lattice fringes evidencing a lattice spacing value $(0.282 \mathrm{~nm})$, confirming that also in this case the nanocubes are terminated by $\{100\}$ surfaces. The RG$\mathrm{Co}_{3} \mathrm{O}_{4}$ sample, however, shows a more heterogeneous morphology, since both shapeless spherical and cubic $\mathrm{Co}_{3} \mathrm{O}_{4}$ NPs are observed in Figure 1c,f. In addition to the morphology, another important difference deduced from the lattice fringe analysis of the $\mathrm{RG}-\mathrm{Co}_{3} \mathrm{O}_{4}$ is the nature of the exposed surface. From high-resolution images, a lattice spacing value of $0.47 \mathrm{~nm}$ can be determined, indicating the presence of $\{111\}$ terminated NPs. ${ }^{47}$ This may be attributed to the different surface chemistry of the supporting graphene sheets and in particular to the absence of $\mathrm{N}$ functionalities, which has been reported in the literature to play an important role in the early stage of nucleation and control of the NP shape. ${ }^{34,35,48}$ In fact, photoemission measurements have demonstrated that the pyridinic functionalities in NG may coordinate Co centers, which therefore may act as nucleation centers for the growth of the nanocubes. ${ }^{49}$ Such a strong interaction between the two materials is also expected to affect the final morphology of the nanocomposite, given the possible modification in the interfacial stability between the two materials. ${ }^{35}$

The NG- $\mathrm{Co}_{3} \mathrm{O}_{4}$ nanocomposites were also investigated by SEM (Figure $\mathrm{S} 3$ in the Supporting Information). Figure S3 confirms the formation of $\mathrm{Co}_{3} \mathrm{O}_{4}$ nanocubes on a large scale, which are quite homogeneously dispersed on the graphene sheets. Some aggregates can be identified, especially in the case of higher $\mathrm{Co}_{3} \mathrm{O}_{4}$ loading. The large-scale morphology of graphene is the same for both the $\mathrm{N}$-doped and $\mathrm{RG}$ samples. Figure 2 reports the Raman spectra of the graphene- $\mathrm{Co}_{3} \mathrm{O}_{4}$ nanocomposites. All of the samples show bands that are 

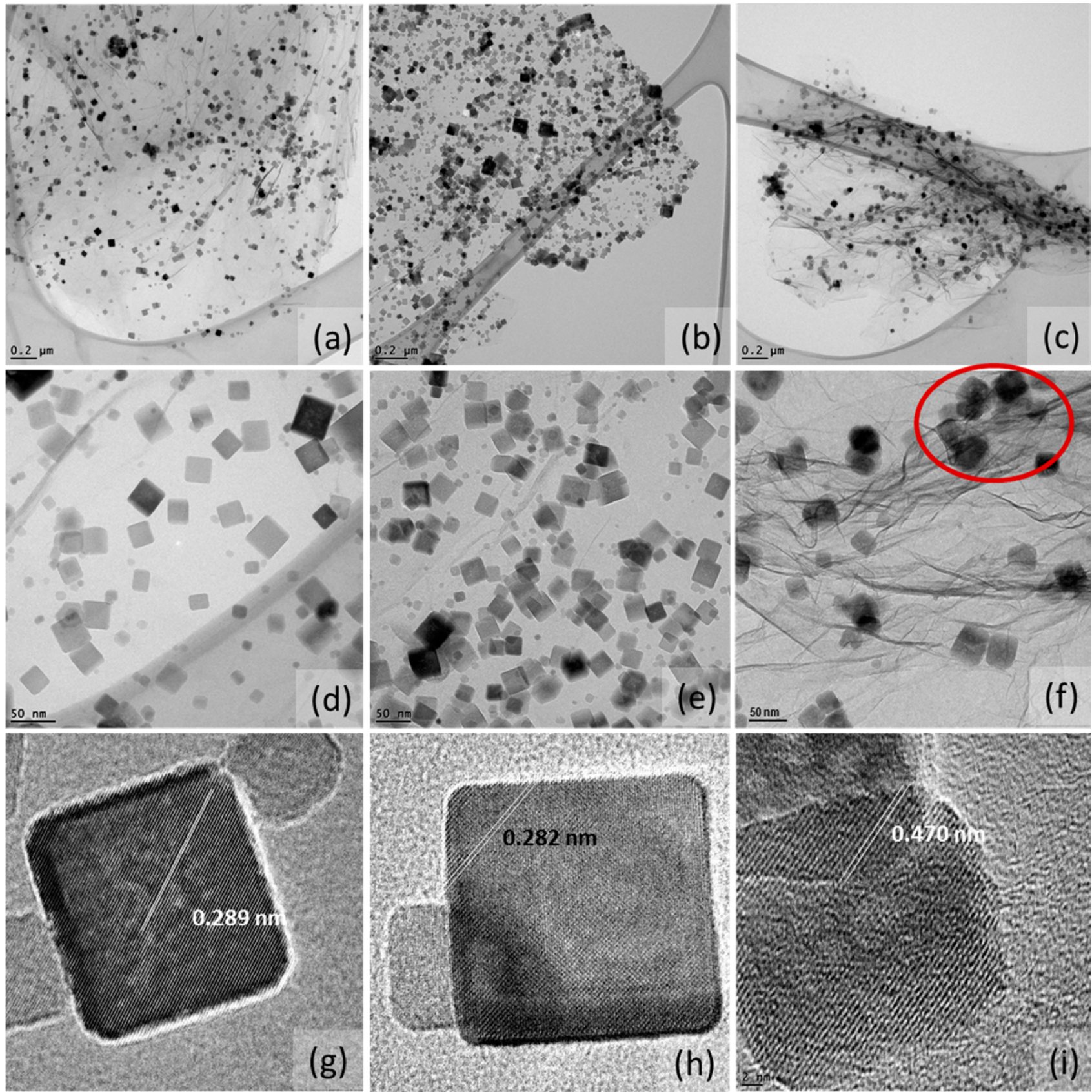

Figure 1. Low $(\mathrm{a}-\mathrm{c})$ - and high-magnification $(\mathrm{d}-\mathrm{f})$ TEM images as well as HR-TEM images $(\mathrm{g}-\mathrm{i})$ for the NG- $\mathrm{Co}_{3} \mathrm{O}_{4}-30(\mathrm{a}, \mathrm{d}, \mathrm{g}), \mathrm{NG}-\mathrm{Co}_{3} \mathrm{O}_{4}-40$ $(b, e, h)$ and $\mathrm{RG}-\mathrm{Co}_{3} \mathrm{O}_{4}-30$ (c, f, i) samples. The inset in image (e) shows the presence of agglomerated NPs in NG-Co $\mathrm{O}_{4}-40$.

characteristics of the $\mathrm{Co}_{3} \mathrm{O}_{4}$ spinel (at 193, 481, 617, and 690 $\mathrm{cm}^{-1}$; see the red stars), confirming the TEM results. ${ }^{50}$ No additional bands corresponding to different oxides or oxohydroxides of cobalt are detected, indicating that the synthesis procedure is very selective toward the production of pure spinel phase, in agreement with previous reports. ${ }^{51}$

In addition, the samples containing graphene exhibit two bands at 1319 and $1592 \mathrm{~cm}^{-1}$, which are attributed to the inplane vibrations of the defective (D) and graphitic (G) domains of the graphene matrix, respectively. The ratio between the intensity of the $\mathrm{D}$ and $\mathrm{G}$ bands $\left(I_{\mathrm{D}} / I_{\mathrm{G}}\right)$ provides information about the degree of defectivity of the carbon material. The positions of the D and G bands for NG are 1310 and 1592 $\mathrm{cm}^{-1}$ (black stars in Figure 2), respectively, and the intensity ratio $\left(I_{\mathrm{D}} / I_{\mathrm{G}}\right)$ is 1.2 , which is slightly higher than that of $\mathrm{RG}$
(1.08) and is mainly due to the presence of $\mathrm{N}$ defects. When $\mathrm{Co}_{3} \mathrm{O}_{4}$ is introduced, the $I_{\mathrm{D}} / I_{\mathrm{G}}$ ratio further increases up to 1.35, indicating that the formation of $\mathrm{Co}_{3} \mathrm{O}_{4}$ creates additional defects in the carbon matrix, suggesting a strong interaction between the two moieties.

The successful doping of graphene oxide (GO) with nitrogen and the chemical composition of the nanocomposites were investigated by XPS. The photoemission measurements of the NG- $\mathrm{Co}_{3} \mathrm{O}_{4}-30$ sample are reported in Figure 3 as an example, while the data obtained for the other graphene- $\mathrm{Co}_{3} \mathrm{O}_{4}$ samples are shown in Figures S4-S6 in the Supporting Information. The survey spectra show peaks corresponding only to the presence of elements such as $\mathrm{C}, \mathrm{N}, \mathrm{O}$, and $\mathrm{Co}$, indicating that the nanohybrids do not contain impurities. 


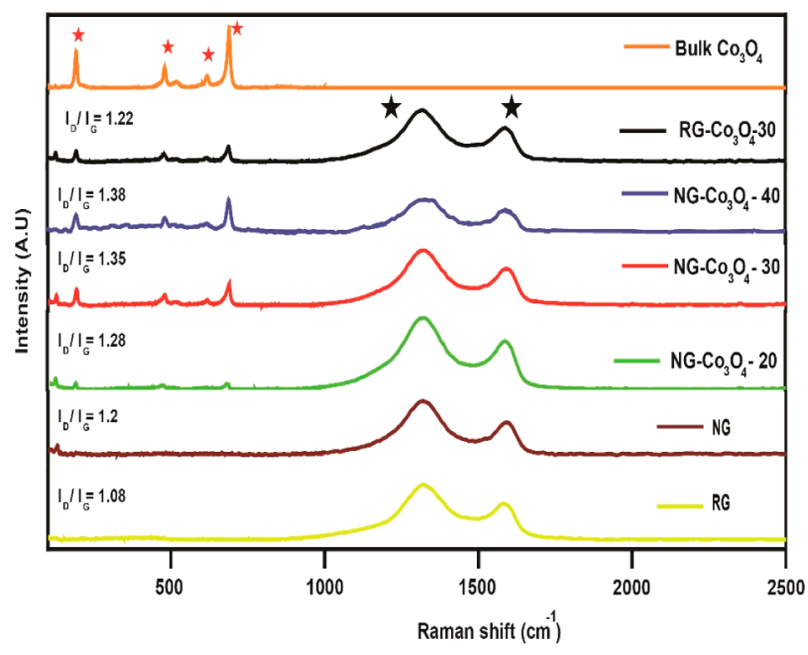

Figure 2. Raman spectra of RG- $\mathrm{Co}_{3} \mathrm{O}_{4}-30$ and NG- $\mathrm{Co}_{3} \mathrm{O}_{4}$ nanocomposites with different oxide loadings. The Raman spectra for NG, $\mathrm{RG}$, and $\mathrm{Co}_{3} \mathrm{O}_{4}$ spinel are also shown as reference.

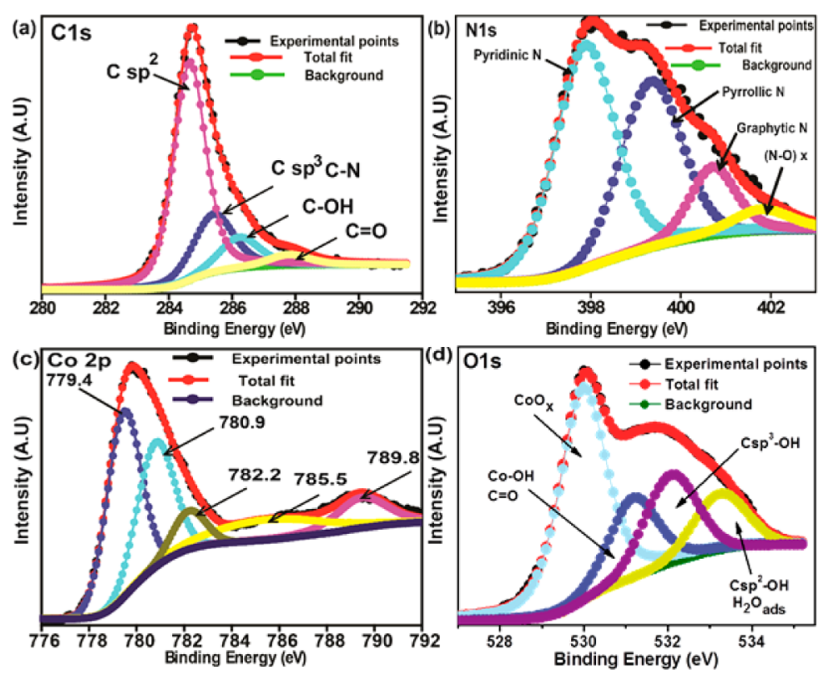

Figure 3. $\mathrm{C} 1 \mathrm{~s}(\mathrm{a}), \mathrm{N} 1 \mathrm{~s}(\mathrm{~b})$, Co $2 \mathrm{p}(\mathrm{c})$, and $\mathrm{O}$ 1s (d) photoemission lines for the NG- $\mathrm{Co}_{3} \mathrm{O}_{4}-30$ sample. The whole set of photoemission measurements for the graphene- $\mathrm{Co}_{3} \mathrm{O}_{4}$ samples is reported in Figures S4-S6 in the Supporting Information.

The deconvolution of the $\mathrm{C} 1 \mathrm{~s}$ spectrum into chemically shifted components shows the presence of $\mathrm{C}=\mathrm{C}(284.5 \mathrm{eV})$, $\mathrm{C}-\mathrm{N}(285.6 \mathrm{eV}), \mathrm{C}-\mathrm{OH}(286.3 \mathrm{eV})$ and $\mathrm{C}=\mathrm{O}(287.8 \mathrm{eV})$ species in all the NG-based samples, confirming the N-doping (see Table $\mathrm{S} 1$ in the Supporting Information). ${ }^{52-54}$ The analysis of the $\mathrm{N}$ 1s photoemission line (Figure $3 \mathrm{~b}$ ) suggests the presence of pyridinic, pyrrolic, and graphitic nitrogen species at $\mathrm{BE}$ values of $397.5,399.1$, and $400.7 \mathrm{eV}$, respectively, as well as nitrogen oxides at $401.9 \mathrm{eV}$ (see Table S1). ${ }^{52}$ The nitrogen doping percentage was calculated from the intensity of the $\mathrm{N}$ 1s and $\mathrm{C} 1 \mathrm{~s}$ photoemission lines, taking into account the corresponding sensitivity factors, and resulted to be around $3.9-4.9$ atom $\%$. The nature of the $\mathrm{N}$ species was determined as $49 \%$ pyridinic, $34 \%$ pyrrolic, and $12 \%$ graphitic $\mathrm{N}$ and $4.5 \%$ nitrogen oxides. Among them, pyridinic groups are expected to act as anchoring sites for the growth of $\mathrm{Co}_{3} \mathrm{O}_{4}$ due to their coordination capabilities. ${ }^{34}$ In addition, it has been reported in the literature that graphitic nitrogen is responsible for the electronic $\mathrm{n}$-doping of the graphene sheets. ${ }^{55}$ Figure $3 \mathrm{c}$ shows the Co $2 p$ photoemission line that is representative of all samples. All of the Co $2 p$ spectra show the same shape with two peaks at 781 and $795 \mathrm{eV}$ that are due to the spin-orbit coupling. The multiplet structure and relative intensity of the satellites of the Co $2 \mathrm{p}_{3 / 2}$ lines is characteristic of $\mathrm{Co}_{3} \mathrm{O}_{4}$ spinel, as the analysis depicted in Figure $3 c$ evidences. ${ }^{56,57}$ The photoemission peak can be fitted with five components at $779.4,780.9,782.2,785.5$, and $789.8 \mathrm{eV}$, which are in good agreement with the values reported in the literature for the spinel type $\mathrm{Co}_{3} \mathrm{O}_{4}$ phase. As an example in Figure 3d we show the $\mathrm{O} 1 \mathrm{~s}$ spectrum of the $\mathrm{NG}-\mathrm{Co}_{3} \mathrm{O}_{4}-30$ sample. Four components can be clearly identified: the peak at $529.9 \mathrm{eV}$ is due to the $\mathrm{O}^{2-}$ anions in $\mathrm{Co}_{3} \mathrm{O}_{4}$, the feature at $531.2 \mathrm{eV}$ is connected both to hydroxyl species on the oxides and carbonyl groups present on NG, the component at $532.1 \mathrm{eV}$ is indicative of aliphatic alcohols $\left(\mathrm{C}\left(\mathrm{sp}^{3}\right)-\mathrm{OH}\right)$, and finally the peak at $533.2 \mathrm{eV}$ may be associated with phenol groups $\left(\mathrm{C}\left(\mathrm{sp}^{2}\right)-\mathrm{OH}\right)$ and adsorbed water (see Table S1). ${ }^{54}$ Moreover, from XPS measurements, the surface composition of the different samples was obtained. The results are given in Table S2 in the Supporting Information. Hence, the XPS results strongly suggest the formation of $\mathrm{Co}_{3} \mathrm{O}_{4}$ spinel and confirm the $\mathrm{N}$ doping of graphene.

2.1. Electrochemical Analysis. The electrochemical activity of the graphene- $\mathrm{Co}_{3} \mathrm{O}_{4}$ nanocomposites toward the CO2RR was investigated by linear sweep voltammetry (LSV). Figure $4 \mathrm{a}$ shows the LSV for the different electrocatalysts. At potentials more negative than $-1.1 \mathrm{~V}, \mathrm{H}_{2}$ evolution takes place under both $\mathrm{N}_{2-}$ and $\mathrm{CO}_{2}$-saturated conditions. When the electrolyte solution is saturated with $\mathrm{CO}_{2}$, a clear peak related to the electroreduction of $\mathrm{CO}_{2}$ is observed at more positive potentials (in comparison with the potential at which HER occurs). For NG- $\mathrm{Co}_{3} \mathrm{O}_{4}-20$, the onset potential and the peak potential are observed at -0.89 and $-0.95 \mathrm{~V}$, respectively. For $\mathrm{NG}-\mathrm{Co}_{3} \mathrm{O}_{4}-30$, the onset potential is shifted to $-0.82 \mathrm{~V}$ and a significant increase in the $\mathrm{CO}_{2}$ reduction current is obtained, in comparison to $\mathrm{NG}-\mathrm{Co}_{3} \mathrm{O}_{4}-20$. These values are comparable with those for other advanced cobalt-based catalysts ${ }^{27}$ and are even better (i.e., more positive) with respect to other nonprecious-metal catalysts. ${ }^{31,58,59}$ The peak current density of $\mathrm{NG}-\mathrm{Co}_{3} \mathrm{O}_{4}-30\left(10.50 \mathrm{~mA} \mathrm{~cm}{ }^{-2}\right)$ is 2.5 times higher than that obtained for NG- $\mathrm{Co}_{3} \mathrm{O}_{4}-20\left(4.1 \mathrm{~mA} / \mathrm{cm}^{2}\right)$. The better performance of this sample could be ascribed to the higher loading of $\mathrm{Co}_{3} \mathrm{O}_{4}$ and, therefore, to the higher number of active centers. However, a further increment in the loading of $\mathrm{Co}_{3} \mathrm{O}_{4}$ has a negative effect on the electrochemical activity, since a decrease in the current density $\left(6.30 \mathrm{~mA} \mathrm{~cm}^{-2}\right)$ is observed for the NG-Co $\mathrm{O}_{4}-40$ sample. This result may be attributed to the agglomeration of $\mathrm{Co}_{3} \mathrm{O}_{4}$ nanocubes observed by TEM, which may reduce the exposed active sites.

Another important tool to evaluate the kinetics of the electrocatalytic reaction is the Tafel plot derived from the linear sweep voltammograms. Figure $\mathrm{S} 7 \mathrm{a}$ in the Supporting Information shows the Tafel plots for the $\mathrm{NG}-\mathrm{Co}_{3} \mathrm{O}_{4}$ and $\mathrm{RG}-\mathrm{Co}_{3} \mathrm{O}_{4}-30$ catalysts. The lowest Tafel slope is displayed by $\mathrm{NG}-\mathrm{Co}_{3} \mathrm{O}_{4}-30\left(97 \mathrm{mV} \mathrm{dec}{ }^{-1}\right)$, demonstrating its high intrinsic catalytic activity with respect to NG-Co $\mathrm{O}_{4}-40\left(121 \mathrm{mV} \mathrm{dec}^{-1}\right)$, $\mathrm{NG}-\mathrm{Co}_{3} \mathrm{O}_{4}-20\left(107 \mathrm{mV} \mathrm{dec}{ }^{-1}\right)$, and $\mathrm{RG}-\mathrm{Co}_{3} \mathrm{O}_{4}(210 \mathrm{mV}$ $\operatorname{dec}^{-1}$ ).

A value of $118 \mathrm{mV} / \mathrm{dec}$ (as typical of bulk $\mathrm{Co}_{3} \mathrm{O}_{4}$ ) indicates that the rate-determining step of the reaction is the initial transfer of one electron to $\mathrm{CO}_{2}$, whereas a Tafel slope of 59 $\mathrm{mV} / \mathrm{dec}$ suggests a reaction path characterized by a reversible 

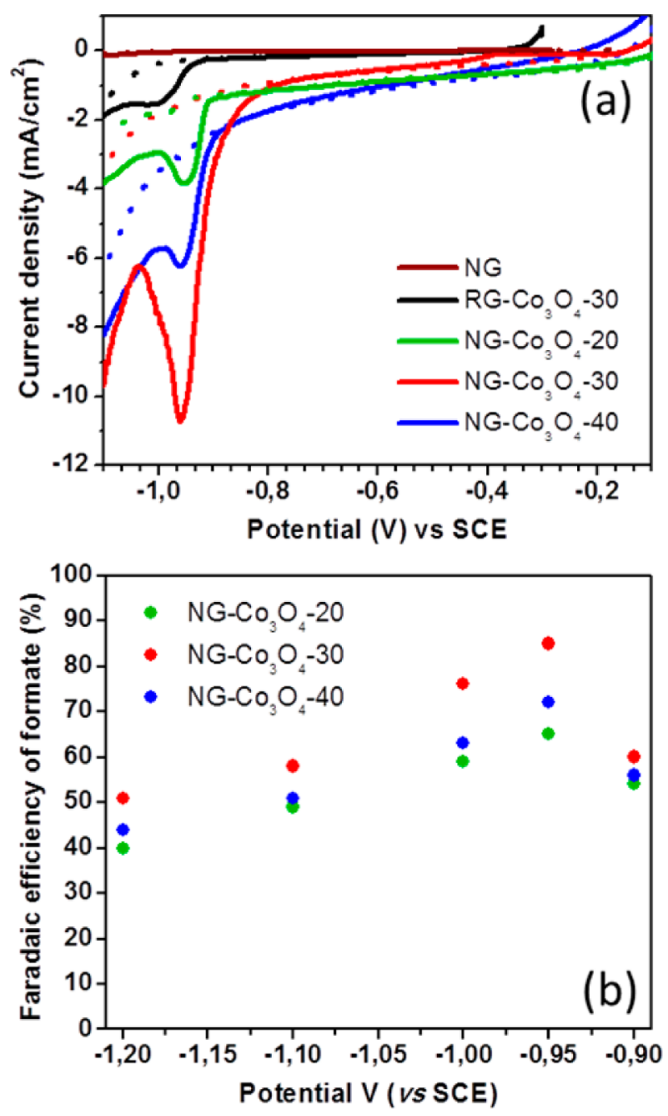

Figure 4. (a) Linear sweep voltammograms in $\mathrm{N}_{2}$ (dotted line)- and $\mathrm{CO}_{2}$-saturated (solid line) $0.1 \mathrm{M} \mathrm{KHCO}_{3}$ at room temperature and at a scan rate of $5 \mathrm{mV} \mathrm{s}^{-1}$. (b) Faradaic efficiency to formate at different potentials for the graphene- $\mathrm{Co}_{3} \mathrm{O}_{4}$ nanocomposites. The currents shown in (a) are normalized by the geometric area. The corresponding data normalized by the oxide mass are shown in Figure $S 8$ in the Supporting Information.

transfer of on electron to $\mathrm{CO}_{2}$ followed by a chemical ratedetermining step, which may consist of the protonation of $\mathrm{CO}_{2}{ }^{--}$or migration to a different site on the electrode surface. ${ }^{60}$

The lower Tafel slope values obtained for NG-Co $\mathrm{O}_{4}-30$ and $\mathrm{NG}-\mathrm{Co}_{3} \mathrm{O}_{4}-20$ suggest that, as the nanocube dimensions decrease, the formation of $\mathrm{CO}_{2}^{--}$is progressively facilitated. This is likely connected to the change of the electronic properties of nanocubes, which as they get smaller are more and more affected by the interaction with the substrate and may present additional electronic states, as demonstrated for 1.72 nm thick $\mathrm{Co}_{3} \mathrm{O}_{4}$ nanosheets ${ }^{27}$ and ultrathin $\mathrm{CoO}_{x}$ layers. ${ }^{61}$

The enhanced performance displayed by the $\mathrm{NG}-\mathrm{Co}_{3} \mathrm{O}_{4}$ samples can be further explained by electrochemical active surface area analysis. Among the prepared catalysts, NG- $\mathrm{Co}_{3} \mathrm{O}_{4^{-}}$ 30 shows the highest ECSA of $5.8 \mathrm{~cm}^{2}$ in comparison to the other samples such as $\mathrm{NG}-\mathrm{Co}_{3} \mathrm{O}_{4}-40\left(3.85 \mathrm{~cm}^{2}\right), \mathrm{NG}-\mathrm{Co}_{3} \mathrm{O}_{4}$ $20\left(2.40 \mathrm{~cm}^{2}\right)$, and $\mathrm{RG}-\mathrm{Co}_{3} \mathrm{O}_{4}\left(1.56 \mathrm{~cm}^{2}\right)$ (detailed ECSA calculations are given in the Supporting Information, Table S3, and Figure S9). Moreover, in order to get more precise information on the specific activity, we normalized the current observed at $-0.95 \mathrm{~V}$ by the mass of cobalt determined by photoemission measurements. Figure $S 8$ in the Supporting Information shows the comparative mass activity analysis for the NG- $\mathrm{Co}_{3} \mathrm{O}_{4}$ and $\mathrm{RG}-\mathrm{Co}_{3} \mathrm{O}_{4}$ samples with respect to the loading of $\mathrm{Co}_{3} \mathrm{O}_{4}$. Among the catalysts, the highest mass activity is observed for NG- $\mathrm{Co}_{3} \mathrm{O}_{4}-30(44.20 \mathrm{~mA} / \mathrm{mg}$ of $\left.\mathrm{Co}_{3} \mathrm{O}_{4}\right)$ in comparison to other catalysts such as $\mathrm{NG}-\mathrm{Co}_{3} \mathrm{O}_{4}-40$ $\left(20.05 \mathrm{~mA} / \mathrm{mg}\right.$ of $\left.\mathrm{Co}_{3} \mathrm{O}_{4}\right)$, NG- $\mathrm{Co}_{3} \mathrm{O}_{4}-20(29.50 \mathrm{~mA} / \mathrm{mg}$ of $\left.\mathrm{Co}_{3} \mathrm{O}_{4}\right)$, and $\mathrm{RG}-\mathrm{Co}_{3} \mathrm{O}_{4}\left(9.2 \mathrm{~mA} / \mathrm{mg}\right.$ of $\left.\mathrm{Co}_{3} \mathrm{O}_{4}\right)$. Surprisingly, $\mathrm{NG}-\mathrm{Co}_{3} \mathrm{O}_{4}-20$ shows higher activity than $\mathrm{NG}-\mathrm{Co}_{3} \mathrm{O}_{4}-40$, demonstrating that it is possible to achieve a high catalytic performance even with minimum catalyst loading and that an excessive loading promotes the aggregation of NPs rather than an effective increase in activity.

Electrolysis tests for CO2RR at different potentials in the range between -0.9 and $-1.2 \mathrm{~V}$ were conducted to quantify the reaction byproducts and determine the stability of the catalysts (Figure S7b in the Supporting Information). The analysis of the electrolytic solution at different times of electrolysis by ${ }^{1} \mathrm{H}$ NMR has evidenced the formation of formate ions only, and no other species bearing hydrogen groups (methanol or formaldehyde) (see Table 1 and Figure S10 in the Supporting Information). The possible presence of volatile byproducts produced by the $\mathrm{CO}_{2}$ reaction has been verified by gas chromatography. Surprisingly, no other species bearing carbon such as $\mathrm{CO}$ and $\mathrm{CH}_{4}$ were detected, proving the high selectivity of the graphene- $\mathrm{Co}_{3} \mathrm{O}_{4}$ nanocomposites toward the production of formate. These data are in good agreement with previous works from the literature ${ }^{62}$ showing that cobalt oxide based materials and, more in general, metal oxides (e.g., $\mathrm{Ga}_{2} \mathrm{O}_{3}$, $\mathrm{SnO}_{2}$ ) may achieve good catalytic activity but are able to reduce selectively $\mathrm{CO}_{2}$ only to formate, whereas other products such as $\mathrm{CO}$, methanol, and alkanes are not usually produced. In general, it is reported that the reaction path toward formate is favored by an adsorption of the $\mathrm{CO}_{2}{ }^{--}$intermediates through the oxygen atoms, whereas the formation of $\mathrm{CO}$ and other more reduced products requires binding through the $\mathrm{C}$ atom. ${ }^{63}$

The $i-t$ curves at $-0.95 \mathrm{~V}$ are shown in Figure $S 7 \mathrm{~b}$ in the Supporting Information, whereas the calculated Faradaic efficiency to formate at different applied potentials is reported in Figure 4b. NG- $\mathrm{Co}_{3} \mathrm{O}_{4}-30$ displays a maximum Faradaic efficiency of $83 \%$ at $-0.95 \mathrm{~V}$, which is comparatively higher than those of NG- $\mathrm{Co}_{3} \mathrm{O}_{4}-40(72 \%)$ and NG- $\mathrm{Co}_{3} \mathrm{O}_{4}-20$ (64\%).

Quite interestingly, the Faradaic efficiency is only weakly dependent on the applied potential, differently from other materials such as $\mathrm{Pd}^{64}$ and other metals ${ }^{65}$ where, on the other hand, the efficiency for the CO2RR quickly decreases at more

Table 1. Summary of the Electrochemical Performance of the NG-Co $\mathrm{O}_{4}$-Based Electrocatalysts toward the $\mathrm{CO}_{2} \mathrm{Reduction}$ Reaction

\begin{tabular}{|c|c|c|c|c|c|c|}
\hline sample & $\begin{array}{c}\text { onset } \\
\text { potential } \\
(\mathrm{V} \text { vs } \mathrm{SCE})\end{array}$ & $\begin{array}{c}\text { peak } \\
\text { potential } \\
(\mathrm{V} \text { vs } \mathrm{SCE})\end{array}$ & $\begin{array}{l}\text { current density } \\
\left(\mathrm{mA} / \mathrm{cm}^{2} \text { at peak }\right. \\
\text { potential })\end{array}$ & $\begin{array}{l}\text { overpotential } \\
\text { (V) }\end{array}$ & $\begin{array}{l}\text { quantity of formic acid at }-0.95 \mathrm{~V} \\
\text { for } 8 \mathrm{~h}(\mathrm{mmol})\end{array}$ & $\begin{array}{l}\text { Faradaic efficiency of formate at }-0.95 \mathrm{~V} \\
(\%)\end{array}$ \\
\hline $\mathrm{NG}-\mathrm{Co}_{3} \mathrm{O}_{4}-20$ & -0.890 & -0.950 & 4.1 & 0.295 & 1.59 & 64 \\
\hline $\mathrm{NG}-\mathrm{Co}_{3} \mathrm{O}_{4}-30$ & -0.820 & -0.958 & 10.50 & 0.235 & 3.14 & 83 \\
\hline $\mathrm{NG}-\mathrm{Co}_{3} \mathrm{O}_{4}-40$ & -0.885 & -0.962 & 6.30 & 0.284 & 2.16 & 72 \\
\hline
\end{tabular}


reducing potential because of competition with the hydrogen evolution reaction.

Moreover, as seen in Figure $\mathrm{S} 7 \mathrm{~b}$ in the Supporting Information, $\mathrm{NG}-\mathrm{Co}_{3} \mathrm{O}_{4}-30$ displays a stable performance throughout the electrolysis without any variation in the current density, while the Faradaic efficiency of $83 \%$ is maintained (Figure 4b). NG- $\mathrm{Co}_{3} \mathrm{O}_{4}-40$ and NG- $\mathrm{Co}_{3} \mathrm{O}_{4}-20$ give lower current densities, in comparison to NG- $\mathrm{Co}_{3} \mathrm{O}_{4}-30$. However, $\mathrm{NG}-\mathrm{Co}_{3} \mathrm{O}_{4}-40$ shows a gradual increase in the current density with time, which could be attributed to an initial activation (reduction of $\mathrm{Co}_{3} \mathrm{O}_{4}$ to $\mathrm{CoO}$ as seen below) under the action of a constant reducing potential.

To identify the real catalytic phase and determine the stability of $\mathrm{Co}_{3} \mathrm{O}_{4}$ under reaction conditions, we completed a study performed on the powders with the investigation of the $\mathrm{Co}_{3} \mathrm{O}_{4}$ model system in UHV following a previous work by some of us. ${ }^{61}$ With this aim, we combined in situ photoemission measurements with electrochemistry to determine the chemical changes of $\mathrm{Co}_{3} \mathrm{O}_{4}$ under $\mathrm{CO} 2 \mathrm{RR}$ conditions. Forty monolayers (i.e., a film with a thickness of $8 \mathrm{~nm}$ ) of $\mathrm{Co}_{3} \mathrm{O}_{4}$ were grown on $\mathrm{Pd}(100)$ to avoid the exposure of the metal substrate to the electrolyte. The presence of $\mathrm{a} \mathrm{Co}_{3} \mathrm{O}_{4}$ phase was confirmed by low-energy electron diffraction and XPS measurements. $^{61}$ Figure 5 shows the Co 2 p region for the "as prepared" sample. As seen above for the powders, the Co $2 \mathrm{p}_{3 / 2}$ peak exhibits a multiplet structure and relative intensity of the
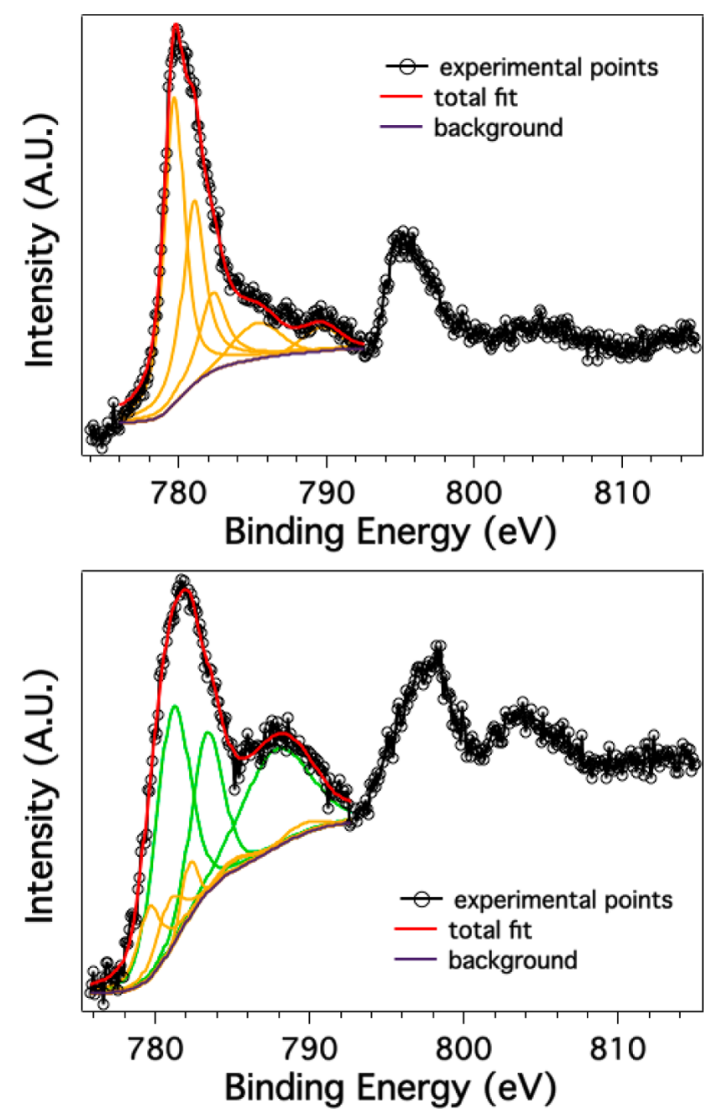

Figure 5. Co $2 \mathrm{p}$ photoemission lines and corresponding deconvolution into chemical shifted components, for the $\mathrm{Co}_{3} \mathrm{O}_{4} / \mathrm{Pd}(100)$ sample before (top) and after (bottom) the polarization at $-1.0 \mathrm{~V}$ in $\mathrm{CO}_{2}$-saturated $0.1 \mathrm{M} \mathrm{KHCO}_{3}$ at room temperature. Yellow curves are the components related to the spinel phases whereas the green curves are the components related to $\mathrm{CoO}$. satellites characteristic of the $\mathrm{Co}_{3} \mathrm{O}_{4}$ spinel structure. After the synthesis, the sample was transferred to the electrochemical cell through the UHV-EC transfer system and polarized at $-1.0 \mathrm{~V}$ in $\mathrm{CO}_{2}$-saturated $0.1 \mathrm{M} \mathrm{KHCO}_{3}$. Subsequently, the chemical changes induced under reaction conditions were investigated by XPS. The analysis of the Co $2 p_{3 / 2}$ peak of the sample polarized at $-1.0 \mathrm{~V}$ indicates a clear reduction of $\mathrm{Co}_{3} \mathrm{O}_{4}$ to $\mathrm{CoO}$. Therefore, for the first time, it is demonstrated that $\mathrm{Co}_{3} \mathrm{O}_{4}$ is not stable under $\mathrm{CO} 2 \mathrm{RR}$ conditions, being reduced to $\mathrm{CoO}$, which is the catalytically active phase for $\mathrm{Co}_{3} \mathrm{O}_{4}$-based systems. The electrochemical reduction of $\mathrm{Co}_{3} \mathrm{O}_{4}$ to $\mathrm{CoO} / \mathrm{Co}$ was also confirmed for the powders by performing $\mathrm{CVs}$ in the absence of $\mathrm{CO}_{2}$ (Figure S11). The reduction of $\mathrm{Co}^{3+}$ to $\mathrm{Co}^{2+}$ is attained in the potential range where the $\mathrm{CO}_{2}$ reduction takes place. This finding is consistent with other works that clearly demonstrated how the catalytic activity of several electrocatalitic systems based on oxides is due to the "in situ" formation of new phases. ${ }^{66,67}$

This is in agreement with recent work of Gao et al., ${ }^{28}$ which shows that the $\mathrm{CoO} / \mathrm{Co}$ intermixed phase is responsible for a very high activity toward the ORR. In the present case the role of the metal phase is adopted by NG: as a matter of fact, nitrogen-doped carbon materials present metal-like behavior and are able to donate charge to supported nanoparticles, favoring their reduction and stabilizing a low oxidation state. This tendency has been experimentally demonstrated for the $\mathrm{Co}_{3} \mathrm{O}_{4} / \mathrm{NG}$ system where, by means of spatially resolved spectroscopic measurements, a clear correlation was observed between the presence of nitrogen atoms and the transformation of $\mathrm{Co}^{3+}$ to $\mathrm{Co}^{2+68}$. Previous works on other easily oxidizable metals ${ }^{62,63}$ indicate that a subtle balance between oxide and metal component is responsible for a highly efficient $\mathrm{CO}_{2}$ electroreduction, ${ }^{69}$ where the oxide is needed to reduce activity for direct $\mathrm{H}^{+}$reduction to $\mathrm{H}_{2}$ but nonetheless acts as a reservoir of protons for the intermediate steps of the $\mathrm{CO}_{2}$ reduction.

In order to confirm the formation of such a mixed metal/ metal oxide phase also on powder samples, the $\mathrm{NG}-\mathrm{Co}_{3} \mathrm{O}_{4}-30$ catalyst was investigated by Raman spectroscopy, XPS, GIXRD, and SEM, comparing the results before and after electrolysis (Figures S12-S14 in the Supporting Information). The cubic morphology of the NPs is maintained after the electrochemical treatment; however, photoemission measurements indicate that the surface of the $\mathrm{Co}_{3} \mathrm{O}_{4}$ nanocubes, which is in contact with the electrolyte, is reduced under reaction conditions to $\mathrm{CoO}$ and even a small metal component is observed. Nonetheless, the $\mathrm{Co}_{3} \mathrm{O}_{4}$ in the core remains stable as suggested by Raman spectra. The same indication can be observed on comparison of the GIXRD spectra before and after the electrochemical tests. In the pristine material only the diffraction peaks of $\mathrm{Co}_{3} \mathrm{O}_{4}$ can be observed, whereas after the electrochemical work, two new peaks at 35.3 and $42.6^{\circ}$, attributed to $\mathrm{CoO}$, become visible as well as a faint shoulder at $44^{\circ}$, which may be ascribed to a nascent metal phase. $^{70}$

The transformation from $\mathrm{Co}_{3} \mathrm{O}_{4}$ to $\mathrm{CoO}$ provides an indication of the key role played by the nanoparticle shape: $\mathrm{Co}_{3} \mathrm{O}_{4}$ can be topotactically converted to $\mathrm{CoO}$, since both structures share the same oxygen sublattice and the octahedral cations. From a morphological point of view, the $\{100\}$ surfaces are rather stable on both oxides, whereas $\{111\}$ facets are stable only in the spinel phase, while they represent a highly unstable polar termination for $\mathrm{CoO}$. This suggests than an easy topotactic conversion can be observed for $\{100\}$ oriented nanocubes, whereas for other shapes involving $\{111\}$ facets, a 
more complicated morphological rearrangement would be necessary.

Overall these data confirm previous results on a cobalt-based catalyst that has proven to be extremely selective for the reduction of $\mathrm{CO}_{2}$ to formate and indicate that $\mathrm{N}$-doped graphene plays a crucial stabilization role, but without providing an intrinsic reactivity (as also evidenced directly by the LSV of bare NG reported in Figure 4a). Actually, it has been recently demonstrated that, on $\mathrm{N}$-doped graphene foams, pyridinicbased defects are able to electrochemically convert $\mathrm{CO}_{2}$ to $\mathrm{CO}$ at rather low overpotential. ${ }^{36}$ Similarly, cobalt-based porphyrins and porphyrin-like systems mostly selectively reduce $\mathrm{CO}_{2}$ to CO. ${ }^{1,44}$ Because we are not observing any production of $\mathrm{CO}$, we may deduce that the real catalytic phase is represented by $\mathrm{CoO}_{x}$, and not some $\mathrm{Co}-\mathrm{N}-\mathrm{C}$ species. This demonstrates that the effect of nitrogen-doped graphene is indirect and affects only the morphological and electronic properties of the supported metal oxide, without a direct involvement in the catalytic cycle. Interestingly, the sample NG- $\mathrm{Co}_{3} \mathrm{O}_{4}-30$ provides a rather high Faradaic efficiency at a very low overpotential with respect to other non-precious-metal-based catalysts such as ultrathin $\mathrm{Co}_{3} \mathrm{O}_{4}$ nanosheets, ${ }^{27}$ mixed metal oxides, ${ }^{71}$ copper nanofoams, ${ }^{9}$ copper oxides, ${ }^{59}$ or metal alloys. ${ }^{72}$ Therefore, its catalytic performance is very promising in terms of both selectivity and stability in comparison with those reported in the literature for other metal oxides and noble-metal NPs. ${ }^{58}$

\section{CONCLUSION}

In conclusion, we have developed a simple and potentially highly scalable synthetic protocol for the preparation of $\mathrm{Co}_{3} \mathrm{O}_{4} /$ graphene nanohybrids that can be used as electrocatalysts for the $\mathrm{CO}_{2}$ reduction reaction. When nitrogen-doped graphene is used as a support for the metal oxide, a higher catalytic activity is observed with respect to undoped graphene, indicating that the doping has an important, though indirect, role. Actually, in situ photoemission measurements demonstrate that the nitrogen-doped graphene helps the transformation toward reduced $\mathrm{CoO}$, which is the true active phase under electrocatalytic conditions.

By a comparison of the activity of catalysts with different cobalt oxide loading, it turns out that there is an optimal value of the ratio between active phase and support due to the tradeoff between the maximum number of exposed cobalt sites and minimization of $\mathrm{NP}$ aggregation. The $\mathrm{NG}-\mathrm{Co}_{3} \mathrm{O}_{4}-30$ catalyst shows the highest activity with an onset potential of $-0.82 \mathrm{~V}$ vs SCE with a peak current density of $10.50 \mathrm{~mA} / \mathrm{cm}^{2}$. It also shows high selectivity toward formate formation with a Faradaic efficiency of $83 \%$. The combination of low overpotential and high selectivity makes this $\mathrm{Co}_{3} \mathrm{O}_{4} /$ nitrogen-doped graphene nanohybrid one of the best catalysts among nonprecious metals for the $\mathrm{CO}_{2}$ reduction.

\section{EXPERIMENTAL SECTION}

4.1. Synthesis of Nitrogen-Doped Graphene (NG). Graphene oxide (GO) was synthesized by following the modified Hummer method as reported in detail elsewhere. ${ }^{73}$ Initially, graphite and $\mathrm{KMnO}_{4}$ were mixed together by mechanical grinding. The resulting powder mixture was slowly added to $150 \mathrm{~mL}$ of a $\mathrm{H}_{2} \mathrm{SO}_{4} / \mathrm{H}_{3} \mathrm{PO}_{4}(9 / 1 \mathrm{v} / \mathrm{v})$ solution kept in an ice bath $\left(0\right.$ to $\left.5{ }^{\circ} \mathrm{C}\right)$ with stirring for $6 \mathrm{~h}$. Then, the reaction mixture was heated and maintained at $55{ }^{\circ} \mathrm{C}$ for $12 \mathrm{~h}$. The reaction was quenched by adding slowly a mixture of ice- cold water $(500 \mathrm{~mL})$ and $\mathrm{H}_{2} \mathrm{O}_{2}(3 \mathrm{~mL})$. The resulting yellow solid was washed several times with deionized water and subsequently separated by centrifugation (5000 rpm). Finally, the obtained suspension was dialyzed for 7 days to remove all impurities and lyophilized to give GO as a solid.

An $100 \mathrm{mg}$ amount of GO was mixed with $500 \mathrm{mg}$ of melamine and ground until a uniform powder was obtained. This mixture was transferred into an alumina crucible and heated at $900{ }^{\circ} \mathrm{C}$ with a rate of $15{ }^{\circ} \mathrm{C} \mathrm{min}{ }^{-1}$ under an argon atmosphere for $3 \mathrm{~h}$ in a tubular furnace. Subsequently, the crucible was cooled to room temperature. The resulting black solid was dispersed in deionized water. Several washing and centrifugation cycles were used to remove any impurities. Finally, the resulting precipitate was dried at $60{ }^{\circ} \mathrm{C}$ overnight to give solid NG. Similarly, reduced graphene $(\mathrm{RG})$ was obtained by the same thermal treatment method without adding the melamine.

4.2. Synthesis of $\mathrm{NG}-\mathrm{Co}_{3} \mathrm{O}_{4}$ Electrocatalysts. The nanohybrid made up of $\mathrm{Co}_{3} \mathrm{O}_{4} \mathrm{NPs}$ supported on NG sheets was prepared by following the procedure reported in the literature with some modifications. ${ }^{49}$ Initially, $40 \mathrm{mg}$ of NG and $60 \mathrm{mg}$ of cobalt acetate were dispersed in $15 \mathrm{~mL}$ of an ethanol/ water $(3 / 2 \mathrm{v} / \mathrm{v})$ solution and sonicated for $30 \mathrm{~min}$. The resulting dispersion was transferred into a Teflon-lined hydrothermal reactor and heated at $140{ }^{\circ} \mathrm{C}$ for $12 \mathrm{~h}$. The resulting product was purified by cycles of washing with deionized water and centrifugation and subsequently dried at $60{ }^{\circ} \mathrm{C}$. The obtained sample was denoted as $\mathrm{NG}-\mathrm{Co}_{3} \mathrm{O}_{4}-30(30$ refers to the weight percent of cobalt determined from photoemission analysis). Similarly, NG- $\mathrm{Co}_{3} \mathrm{O}_{4}-20$ and NG$\mathrm{Co}_{3} \mathrm{O}_{4}-40$ samples were synthesized by using $30 \mathrm{mg}$ of NG and $40 \mathrm{mg}$ of cobalt acetate and $20 \mathrm{mg}$ of NG and $75 \mathrm{mg}$ of cobalt acetate, respectively. In addition, to understand the effect of $\mathrm{N}$ doping, we prepared a nanohybrid using pure GO, namely RG$\mathrm{Co}_{3} \mathrm{O}_{4}-30$, which was synthesized by using $40 \mathrm{mg}$ of $\mathrm{RG}$ and 60 $\mathrm{mg}$ of cobalt acetate.

4.3. Physical Characterization. X-ray photoelectron spectroscopy (XPS) measurements were carried out in a custom-made UHV system equipped with an Omicron EA150 electron analyzer and an Omicron DAR $400 \mathrm{X}$-ray source with a dual $\mathrm{Al}-\mathrm{Mg}$ anode, working at a base pressure of $10^{-9} \mathrm{mbar}$. Core level photoemission spectra (C 1s, N 1s, O 1s, and Co $2 p$ regions) were collected at room temperature with a nonmonochromated $\mathrm{Mg} \mathrm{K} \alpha \mathrm{X}$-ray source $(1253.6 \mathrm{eV})$ and using an energy step of $0.1 \mathrm{eV}, 0.5 \mathrm{~s}$ integration time, and $20 \mathrm{eV}$ pass energy. The samples were dispersed in water and drop-casted onto a copper foil. Raman measurements were performed with a ThermoFisher DXR Raman microscope using a laser with an excitation wavelength of $780 \mathrm{~nm}(1 \mathrm{~mW})$, with a $50 \times$ objective (Olympus). Scanning electron microscopy (SEM) images were obtained with a GEMINI column (Zeiss Supra VP35) microscope, equipped with an EDX detector for elemental analysis, operating at an acceleration voltage between 5 and 10 $\mathrm{kV}$. High-resolution transmission electron microscopy (HRTEM) images were obtained using a TITAN (80-300) field emission microscope operated at an acceleration voltage of 300 $\mathrm{kV}$.

4.4. Electrochemical Characterization. The electrochemical measurements were carried out in a custom-made two-compartment cell, where the anode and the cathode were separated by a glass frit. A saturated calomel electrode (SCE) and a Pt wire were used as reference and counter electrodes, respectively. All of the potentials in the text are referred to the 
SCE. The working electrode consisted of $20 \mu \mathrm{L}$ of catalyst ink drop-casted onto a glassy-carbon (GC) electrode and dried in air. The catalyst inks were prepared by dispersing $2 \mathrm{mg}$ of active phase in $0.5 \mathrm{~mL}$ of Milli-Q water and $10 \mu \mathrm{L}$ of Nafion (8 vol \% in alcohol/water solution, Sigma-Aldrich). Before ink deposition, the GC electrode was polished with 1 and $0.25 \mu \mathrm{m}$ diamond paste and sonicated in isopropyl alcohol. A $0.1 \mathrm{M}$ $\mathrm{KHCO}_{3}$ solution, saturated with $\mathrm{N}_{2}$ or $\mathrm{CO}_{2}$ gases, was used as electrolyte. During the electrochemical measurements, the cell was kept under a $\mathrm{CO}_{2}$ atmosphere with constant stirring. The measurements were performed using a PGSTAT101 Autolab potentiostat running with NOVA. Cyclic (CV) and linear sweepvoltammetry (LSV) measurements were carried out between 0 and $-1.1 \mathrm{~V}$ with a scan rate of $0.005 \mathrm{~V} \mathrm{~s}^{-1}$ in order to determine the activity of the samples toward the CO2RR. The electrochemical active surface area (ECSA) was calculated by measuring the roughness factor $R_{\mathrm{f}}$ of the working electrode in the non-Faradaic region (a detailed description of the procedure is given in the Supporting Information).

4.5. Stability Tests and Product Analysis and Quantification. The long-term stability of the catalysts and product analysis were determined by electrolysis experiments at different potentials in the range between -0.9 to $-1.2 \mathrm{~V}$ for 8 h. The liquid products were analyzed and quantified by ${ }^{1} \mathrm{H}$ NMR spectroscopy (Bruker Avance $300 \mathrm{MHz}$ ). The samples for ${ }^{1} \mathrm{H}$ NMR analysis were prepared by mixing an aliquot of the electrolytic solution $(2.0 \mathrm{~mL})$ with deuterated water $\left(\mathrm{D}_{2} \mathrm{O}, 0.4\right.$ $\mathrm{mL})$ and using dimethyl sulfoxide $(1 \mu \mathrm{L})$ as an internal standard. The ${ }^{1} \mathrm{H}$ NMR spectra were acquired with the water presaturation method on a portion $(0.7 \mathrm{~mL})$ of the obtained mixture. The gaseous products $\left(\mathrm{CO}\right.$ and $\left.\mathrm{CH}_{4}\right)$ were determined by gas chromatography (Agilent Technologies 7890A with a 5975C VL MSD mass spectrometer) using a flame ionization detector (FID) and thermal conductivity detector (TID) and $\mathrm{He}$ as a carrier gas. The measurements were carried out by collecting with a syringe $100 \mu \mathrm{L}$ of the gases from the headspace of the airtight electrochemical cell during electrolysis and directly injecting it into the gas chromatograph.

4.6. Synthesis and Characterization of $\mathrm{Co}_{3} \mathrm{O}_{4} / \mathrm{Pd}(100)$ Model System. Thin films of $\mathrm{Co}_{3} \mathrm{O}_{4}$ on $\mathrm{Pd}(100)$ were prepared by physical vapor deposition, by direct evaporation of metal Co on $\mathrm{Pd}(100)$ under an oxygen atmosphere $\left(P_{\mathrm{O} 2}=2 \times\right.$ $10^{-6}$ mbar) at $660 \mathrm{~K}$ using an evaporation rate of $0.35 \mathrm{ML}$ $\min ^{-1}$ (1 ML corresponds to a thickness of $\left.2.02 \AA\right)$. Subsequently, the sample was annealed under $10^{-3} \mathrm{mbar}$ oxygen partial pressure at the same temperature in order to obtain a full oxidation. Previously to the Co deposition, the $\mathrm{Pd}(100)$ substrate was cleaned by repeated cycles of sputtering with $2 \mathrm{keV} \mathrm{Ar}{ }^{+}$ions at $300 \mathrm{~K}$ and annealing at $900 \mathrm{~K}$. The residual carbon was removed in $2.0 \times 10^{-7}$ mbar of oxygen at $700 \mathrm{~K}$ and, subsequently, the adsorbed oxygen was removed by annealing at $900 \mathrm{~K}$.

The chemical composition and chemical changes induced by the electrochemical measurements were analyzed by XPS, as described above for the powders.

The electrochemical measurements were performed in a home-built PEEK microcell. A Pt wire and an $\mathrm{Ag} / \mathrm{AgCl}(3 \mathrm{M}$ $\mathrm{KCl}$ ) electrode placed in a Luggin capillary were used as counter and reference electrodes, respectively. The EC experiments were carried out in $\mathrm{CO}_{2}$-saturated $0.1 \mathrm{M}$ $\mathrm{KHCO}_{3}$ solution. The sample was polarized at $-1.0 \mathrm{~V}$ vs SCE for $600 \mathrm{~s}$. During the measurement, the electrolyte was pumped into the EC cell through a tubing system at $1 \mathrm{~mL}$ $\min ^{-1}$ by a syringe pump (N-101 Pump System Inc.).

The ultrahigh-vacuum (UHV) system and the electrochemical cell used for this study are described in more detail in the Supporting Information.

\section{ASSOCIATED CONTENT}

\section{Supporting Information}

The Supporting Information is available free of charge on the ACS Publications website at DOI: 10.1021/acscatal.7b02166.

Additional characterizations by TEM, Raman spectroscopy, and XPS, NMR spectra of the reaction product, and capacitance data for determining the surface area (PDF)

\section{AUTHOR INFORMATION}

\section{Corresponding Author}

*E-mail for S.A.: stefano.agnoli@unipd.it.

ORCID 웅

Laura Calvillo: 0000-0001-9256-0133

Cristina Tubaro: 0000-0001-7724-735X

Francesco Carraro: 0000-0001-8485-4676

Stefano Agnoli: 0000-0001-5204-5460

Notes

The authors declare no competing financial interest.

\section{ACKNOWLEDGMENTS}

This work was partially supported by the Italian MIUR through the national grant Futuro in Ricerca 2012 RBFR128BEC "Beyond graphene: tailored C-layers for novel catalytic materials and green chemistry" and PRIN project SMARTNESS (PRIN 2015K7FZLH) and by the University of Padova funded project CPDA128318/12, "Study of the catalytic activity of complex graphene nanoarchitectures from ideal to real conditions". The MAECI (Ministero degli Affari Esteri e della Cooperazione Internazionale) is gratefully acknowledged for the bilateral Italy-China GRAPE-MAT project. P.S. acknowledges Fondazione Cariparo for financial support. We thank Prof. Andrea Sartorel for the gas chromatography measurements.

\section{REFERENCES}

(1) Lin, S.; Diercks, C. S.; Zhang, Y.-B.; Kornienko, N.; Nichols, E. M.; Zhao, Y.; Paris, A. R.; Kim, D.; Yang, P.; Yaghi, O. M.; Chang, C. J. Science 2015, 349, 1208-1213.

(2) Kuhl, K. P.; Cave, E. R.; Abram, D. N.; Jaramillo, T. F. Energy Environ. Sci. 2012, 5, 7050.

(3) Costentin, C.; Passard, G.; Robert, M.; Saveant, J. M. J. Am. Chem. Soc. 2014, 136, 11821-11829.

(4) Quadrelli, E. A.; Centi, G.; Duplan, J.-L.; Perathoner, S. ChemSusChem 2011, 4, 1194-1215.

(5) Kuhl, K. P.; Hatsukade, T.; Cave, E. R.; Abram, D. N.; Kibsgaard, J.; Jaramillo, T. F. J. Am. Chem. Soc. 2014, 136, 14107-14113.

(6) Zhu, D. D.; Liu, J. L.; Qiao, S. Z. Adv. Mater. 2016, 28, 34233452.

(7) Yang, N.; Waldvogel, S. R.; Jiang, X. ACS Appl. Mater. Interfaces 2016, 8, 28357-28371.

(8) Lee, S. Y.; Lim, S. Y.; Seo, D.; Lee, J.-Y.; Chung, T. D. Adv. Energy Mater. 2016, 6, 1502207.

(9) Sen, S.; Liu, D.; Palmore, G. T. R. ACS Catal. 2014, 4, 30913095.

(10) Li, F.; Zhao, S.-F.; Chen, L.; Khan, A.; MacFarlane, D. R.; Zhang, J. Energy Environ. Sci. 2016, 9, 216-223. 
(11) Rosen, B. A.; Salehi-Khojin, A.; Thorson, M. R.; Zhu, W.; Whipple, D. T.; Kenis, P. J. A.; Masel, R. I. Science 2011, 334, 643644.

(12) Kim, B.; Hillman, F.; Ariyoshi, M.; Fujikawa, S.; Kenis, P. J. A. J. Power Sources 2016, 312, 192-198.

(13) Verma, S.; Lu, X.; Ma, S.; Masel, R. I.; Kenis, P. J. Phys. Chem. Chem. Phys. 2016, 18, 7075-7084.

(14) Kortlever, R.; Peters, I.; Koper, S.; Koper, M. T. M. ACS Catal. 2015, 5, 3916-3923.

(15) Zhu, W.; Michalsky, R.; Metin, O.; Lv, H.; Guo, S.; Wright, C. J.; Sun, X.; Peterson, A. A.; Sun, S. J. Am. Chem. Soc. 2013, 135, 1683316836.

(16) Gao, D.; Zhou, H.; Wang, J.; Miao, S.; Yang, F.; Wang, G.; Wang, J.; Bao, X. J. Am. Chem. Soc. 2015, 137, 4288-4291.

(17) Hall, A. S.; Yoon, Y.; Wuttig, A.; Surendranath, Y. J. Am. Chem. Soc. 2015, 137, 14834-14837.

(18) Feng, X.; Jiang, K.; Fan, S.; Kanan, M. W. J. Am. Chem. Soc. 2015, 137, 4606-4609.

(19) Oh, S.; Gallagher, J. R.; Miller, J. T.; Surendranath, Y. J. Am. Chem. Soc. 2016, 138, 1820-1823.

(20) Passard, G.; Ullman, A. M.; Brodsky, C. N.; Nocera, D. G. J. Am. Chem. Soc. 2016, 138, 2925-2928.

(21) Manna, P.; Debgupta, J.; Bose, S.; Das, S. K. Angew. Chem., Int. Ed. 2016, 55, 2425-2430.

(22) Singh, S. K.; Dhavale, V. M.; Kurungot, S. ACS Appl. Mater. Interfaces 2015, 7, 21138-21149.

(23) Ramsundar, R. M.; Debgupta, J.; Pillai, V. K.; Joy, P. A. Electrocatalysis 2015, 6, 331-340.

(24) Jin, H.; Wang, J.; Su, D.; Wei, Z.; Pang, Z.; Wang, Y. J. Am. Chem. Soc. 2015, 137, 2688-2694.

(25) Hamdani, M.; Singh, R.; Chartier, P. Int. J. Electrochem. Sci. 2010, 5, 556.

(26) Xie, X.; Shen, W. Nanoscale 2009, 1, 50-60.

(27) Gao, S.; Jiao, X.; Sun, Z.; Zhang, W.; Sun, Y.; Wang, C.; Hu, Q.; $\mathrm{Zu}, \mathrm{X}$.; Yang, F.; Yang, S.; Liang, L.; Wu, J.; Xie, Y. Angew. Chem., Int. Ed. 2016, 55, 698-702.

(28) Gao, S.; Lin, Y.; Jiao, X.; Sun, Y.; Luo, Q.; Zhang, W.; Li, D.; Yang, J.; Xie, Y. Nature 2016, 529, 68-71.

(29) Liang, Y.; Li, Y.; Wang, H.; Zhou, J.; Wang, J.; Regier, T.; Dai, H. Nat. Mater. 2011, 10, 780-786.

(30) Shearer, C. J.; Cherevan, A.; Eder, A. D. Adv. Mater. 2014, 26, 2295-2318.

(31) Lei, F.; Liu, W.; Sun, Y.; Xu, J.; Liu, K.; Liang, L.; Yao, T.; Pan, B.; Wei, S.; Xie, Y. Nat. Commun. 2016, 7, 12697.

(32) Spilarewicz-Stanek, K.; Kisielewska, A.; Ginter, J.; Baluszynska, K.; Piwonski, I. RSC Adv. 2016, 6, 60056-60067.

(33) Sreekanth, N.; Nazrulla, M. A.; Vineesh, T. V.; Sailaja, K.; Phani, K. L. Chem. Commun. 2015, 51, 16061-16064.

(34) Wang, R.; Xu, C.; Sun, J.; Gao, L. Sci. Rep. 2015, 4, 7171.

(35) Duan, J.; Chen, S.; Dai, S.; Qiao, S. Z. Adv. Funct. Mater. 2014, 24, 2072-2078.

(36) Wu, J.; Liu, M.; Sharma, P. P.; Yadav, R. M.; Ma, L.; Yang, Y.; Zou, X.; Zhou, X.-D.; Vajtai, R.; Yakobson, B. I.; Lou, J.; Ajayan, P. M. Nano Lett. 2016, 16, 466-470.

(37) Xu, J.; Kan, Y.; Huang, R.; Zhang, B.; Wang, B.; Wu, K. H.; Lin, Y.; Sun, X.; Li, Q.; Centi, G.; Su, D. ChemSusChem 2016, 9, 10851089.

(38) Breslow, R. Acc. Chem. Res. 1995, 28, 146-153.

(39) Hu, X.-M.; Rønne, M. H.; Pedersen, S. U.; Skrydstrup, T.; Daasbjerg, K. Angew. Chem., Int. Ed. 2017, 56, 6468.

(40) Behar, D.; Dhanasekaran, T.; Neta, P.; Hosten, C. M.; Ejeh, D.; Hambright, P.; Fujita, E. J. Phys. Chem. A 1998, 102, 2870-2877.

(41) Kornienko, N.; Zhao, Y.; Kley, C. S.; Zhu, C.; Kim, D.; Lin, S.; Chang, C. J.; Yaghi, O. M.; Yang, P. J. Am. Chem. Soc. 2015, 137, 14129-14135

(42) Cheng, M.-J.; Kwon, Y.; Head-Gordon, M.; Bell, A. T. J. Phys. Chem. C 2015, 119, 21345-21352.

(43) Yao, S. A.; Ruther, R. E.; Zhang, L.; Franking, R. A.; Hamers, R. J.; Berry, J. F. J. Am. Chem. Soc. 2012, 134, 15632-15635.
(44) Morlanés, N.; Takanabe, K.; Rodionov, V. ACS Catal. 2016, 6, 3092-3095.

(45) Yu, X.-Y.; Meng, Q.-Q.; Luo, T.; Jia, Y.; Sun, B.; Li, Q.-X.; Liu, J.-L.; Huang, X.-J. Sci. Rep. 2013, 3, 2886.

(46) Geng, B.; Zhan, F.; Fang, C.; Yu, N. J. Mater. Chem. 2008, 18, 4977-4984.

(47) Liang, H.; Raitano, J. M.; Zhang, L.; Chan, S.-W. Chem. Commun. 2009, 7569-7571.

(48) Carraro, F.; Calvillo, L.; Cattelan, M.; Favaro, M.; Righetto, M.; Nappini, S.; Píš, I.; Celorrio, V.; Fermín, D. J.; Martucci, A.; Agnoli, S.; Granozzi, G. ACS Appl. Mater. Interfaces 2015, 7, 25685-25692.

(49) Singh, S. K.; Dhavale, V. M.; Kurungot, S. ACS Appl. Mater. Interfaces 2015, 7, 442-451.

(50) Hadjiev, V.; Iliev, M.; Vergilov, I. J. Phys. C: Solid State Phys. 1988, 21, L199.

(51) Yang, J.; Liu, H.; Martens, W. N.; Frost, R. L. J. Phys. Chem. C 2010, 114, 111-119.

(52) Zhang, C.; Wang, B.; Shen, X.; Liu, J.; Kong, X.; Chuang, S. S. C.; Yang, D.; Dong, A.; Peng, Z. Nano Energy 2016, 30, 503-510.

(53) Favaro, M.; Agnoli, S.; Di Valentin, C.; Mattevi, C.; Cattelan, M.; Artiglia, L.; Magnano, E.; Bondino, F.; Nappini, S.; Granozzi, G. Carbon 2014, 68, 319-329.

(54) Ganguly, A.; Sharma, S.; Papakonstantinou, P.; Hamilton, J. J. Phys. Chem. C 2011, 115, 17009-17019.

(55) Xing, Z.; Ju, Z.; Zhao, Y.; Wan, J.; Zhu, Y.; Qiang, Y.; Qian, Y. Sci. Rep. 2016, 6, 26146.

(56) Biesinger, M. C.; Payne, B. P.; Grosvenor, A. P.; Lau, L. W.; Gerson, A. R.; Smart, R. S. C. Appl. Surf. Sci. 2011, 257, 2717-2730.

(57) Tripathy, S. K.; Christy, M.; Park, N.-H.; Suh, E.-K.; Anand, S.; Yu, Y.-T. Mater. Lett. 2008, 62, 1006-1009.

(58) Wang, Z.-L.; Li, C.; Yamauchi, Y. Nano Today 2016, 11, 373391.

(59) Gupta, K.; Bersani, M.; Darr, J. A. J. Mater. Chem. A 2016, 4, 13786-13794.

(60) Zhang, S.; Kang, P.; Meyer, T. J. J. Am. Chem. Soc. 2014, 136, $1734-1737$.

(61) Gragnaniello, L.; Agnoli, S.; Parteder, G.; Barolo, A.; Bondino, F.; Allegretti, F.; Surnev, S.; Granozzi, G.; Netzer, F. P. Surf. Sci. 2010, 604, 2002-2011.

(62) Zhang, L.; Zhao, Z.-J.; Gong, J. Angew. Chem., Int. Ed. 2017, 56, 11326.

(63) Kortlever, R.; Shen, J.; Schouten, J. J. P.; Calle-Vallejo, F.; Koper, M. T. M. J. Phys. Chem. Lett. 2015, 6, 4073-4082.

(64) Min, X.; Kanan, M. W. J. Am. Chem. Soc. 2015, 137, 4701-4708.

(65) Humphrey, J. J. L.; Plana, D.; Celorrio, V.; Sadasivan, S.; Tooze,

R. P.; Rodríguez, P.; Fermín, D. J. ChemCatChem 2016, 8, 952.

(66) Celorrio, V.; Dann, E.; Calvillo, L.; Morgan, D. J.; Hall, S. R.; Fermín, D. J. ChemElectroChem 2016, 3, 283.

(67) Celorrio, V.; Calvillo, L.; Dann, E.; Granozzi, G.; Aguadero, A.; Kramer, D.; Russel, A. E.; Fermín, D. J. Catal. Sci. Technol. 2016, 6, 7231.

(68) Wang, J.; Zhou, J.; Hu, Y.; Regier, T. Energy Environ. Sci. 2013, $6,926-934$.

(69) Lee, C. H.; Kanan, M. W. ACS Catal. 2015, 5, 465-469.

(70) Nam, K. M.; Shim, J. H.; Han, D. W.; Kwon, H. S.; Kang, Y. M.; Li, Y.; Song, H.; Seo, W. S.; Park, J. T. Chem. Mater. 2010, 22, 44464454.

(71) Yadav, V. S. K.; Purkait, M. K. New J. Chem. 2015, 39, 73487354.

(72) Choi, S. Y.; Jeong, S. K.; Kim, H. J.; Baek, I.-H.; Park, K. T. ACS Sustainable Chem. Eng. 2016, 4, 1311-1318.

(73) Marcano, D. C.; Kosynkin, D. V.; Berlin, J. M.; Sinitskii, A.; Sun, Z.; Slesarev, A.; Alemany, L. B.; Lu, W.; Tour, J. M. ACS Nano 2010, 4, $4806-4814$ 